\title{
Recent Advances in the Drought Stress Tolerance in Rice
}

\section{Manu Kumar*}

Department of Bioindustry and Bioresource Engineering, Plant Engineering Research Institute, Sejong University, Seoul 05006, Korea

${ }^{*}$ Corresponding Author: Manu Kumar, PhD

Department of Bioindustry and Bioresource Engineering, Plant Engineering Research Institute, Sejong University, Seoul 05006, Korea,

E-mail: manukumar007@gmail.com,manukumar@sejong.ac.kr

Orchid:- 0000-0003-3490-5062

Running title: Drought stress tolerance in crop plants.

Keywords: Drought Stress; Osmotic stress; Rice; Transcription Factors, Stress

signaling; QTL, Breeding

Word count: 3409

Total number of figures and tables: 1 main figure.

\section{Abstract}


Many studies were done in the development of drought stress-tolerant transgenic plants, including crop plants. Rice is considered to be a vital crop target for improving drought stress tolerance. Much transgenic rice showed improved drought stress tolerance was reported to date. They are genetically engineered plants that are developed by using genes that encode proteins involved in drought stress regulatory networks. These proteins include protein kinases, transcription factors, enzymes related to osmoprotectant or plant hormone synthesis, receptor-like kinase. Of the drought stress-tolerant transgenic rice plants described in this review, most of them display retarded plant growth. In crop crops, plant health is a fundamental agronomic trait that can directly affect yield. By understanding the regulatory mechanisms of retarded plant growth under drought stress, conditions are necessary precursors to developing genetically modified plants that result in high yields.

\section{Introduction}

A twenty-first-century challenge is the production of sufficient food to meet population demands despite reductions in the quantity and quality of arable land and water and increasingly variable weather patterns that are associated with climate change [1]. Crop losses due to extremes environment have risen steadily over the past several decades, and climate models predict an increased incidence of floods, droughts and extreme 
temperatures, salt stress, and cold temperature [2-6]. Integrated climate change and crop production models project declines in the yields of major crops such as corn, wheat and rice with severe ramifications for global food production this century [7-10]. Despite the progressive increase in the production of significant crops through germplasm development and agronomic practices since the 1960s, susceptibility to climate variability has risen owing to higher sowing densities, which increase competition for water and nutrients [11]. The rapid development and adoption of climate-resilient crop genotypes are imperative to ensure global food security.

Rice is the world's most essential cereals crop, with production comparable to that of other crops. In this Review, we cover different recent advances in drought stress tolerance (Figure 1). 


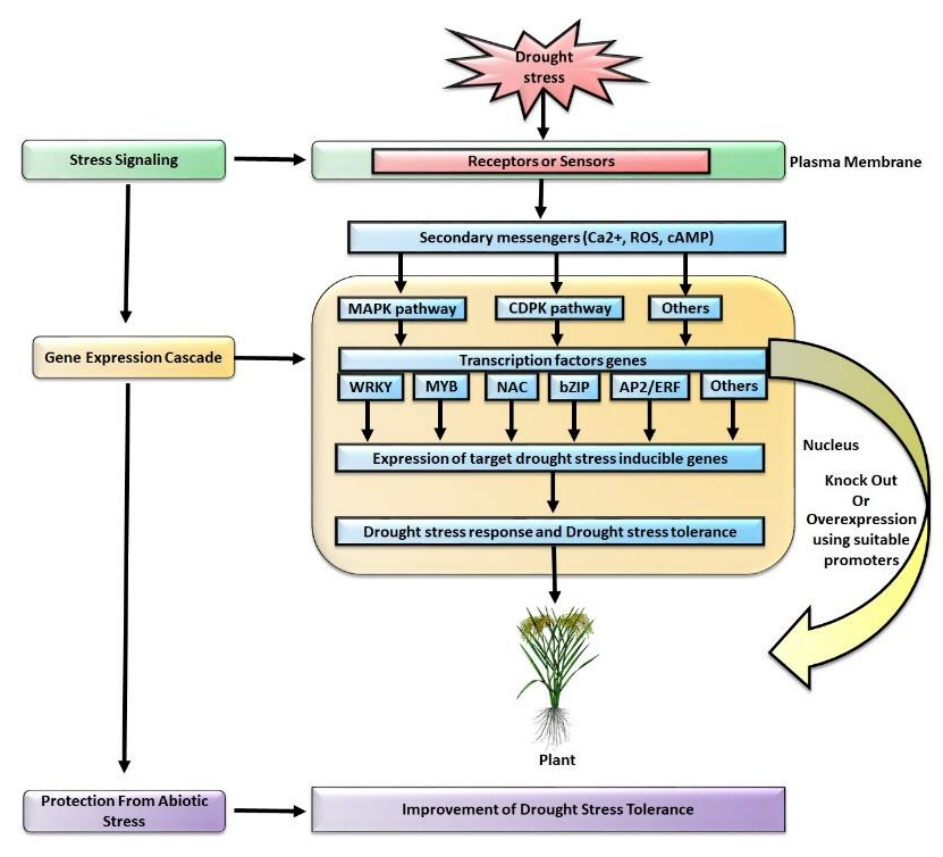

\section{Drought stress tolerance: Rice as a model plant}

\subsection{Genetic engineering approach.}

Plants activate three main categories of genes in response to drought stress [12]. They are (1) genes involved in ion transport (2) regulatory genes involved in controlling transcriptional activities, and (3) novel downstream genes of unknown function reported to be involved in drought tolerance. The Cascades of molecules are involved in the perceiving of environmental signal transfer. These groups of molecules trigger the expression of specific downstream genes leading to appropriate biochemical/physiological responses [13-15]. Many drought-related differential expressed genes have been identified in plants [16-18]. These drought-responsive genes are known 
for their involvement in cellular responses such as "transcriptional regulation and stress perception [19]. These genes code for "phytohormones, Protein kinases, transcription factors, late embryogenesis abundant (LEA), and osmoprotectants proteins [14,19-23] that are involved in drought tolerance.

Plant's response to drought stress is generally via ABA-dependent or ABAindependent manner. In rice, ABA-Responsive cis-Elements (ABRE;PyACGTGG/TC) is abundant compared to soybean and Arabidopsis [24], and ABA concentration dramatically increases in response to drought stress. Increased ABA reportedly involved in (i) $\mathrm{H}_{2} \mathrm{O}_{2}$ accumulation in guard cells due to reduction in loss of water from the plant, (ii) stomatal closure, and (iii) metabolites accumulation and stress proteins (protect cells during stress) [25-27]. The $\mathrm{H}_{2} \mathrm{O}_{2}$ mediated stomatal closure in rice involved in the ABA independent pathway [28].

During drought stress tolerance, the signaling mechanism involves sensing and transferring of dehydration signals from the plasma membrane to the nucleus $[29,30]$. Several protein phosphorylation mechanisms such as receptor-like kinases (RLKs) and mitogen-activated protein kinases (MAPKs) [31-33]. "DROUGHT-HYPERSENSITIVE MUTANT1 (DSM1)"-a protein kinase in rice-scavenges the reactive oxygen species (ROS) produced by drought stress. The dsm1 mutants are hypersensitive to drought 
during the panicle development and seedling stage [34]. The RLK genes such as stressinduced protein kinase 1 (OsSIK1), induced by drought stress in rice. While OsSIK1-Ox rice plants were drought stress-tolerant [35]

Many, transcription factors (TFs) regulating drought stress signaling in rice have also been studied. Many of these TFs bind to cis-regulatory elements of "bZIP, AP2/ERF, MYB, NAC, WRKY, NF-Y, CAMTA, and bHLH" families [36-39]. These TFs overexpression lines displayed drought tolerance. In ABA independent pathway for drought tolerance, DREB (dehydration-responsive element-binding protein) transcription factors involved as a key player. Among DREBs TFs, DREB1/CBF, and DREB2 are involved in drought stress tolerance $[40,41]$. DREB1A-Ox lines were more drought tolerant than rice plants [42]. Similarly, Overexpression of a stress-responsive NAC transcription factor gene ONAC022 improves drought and salt tolerance in rice [43].

Along with drought-responsive elements, proteins such as LEA have been identified for drought stress tolerance [44]. LEA can be accumulated in vegetative tissues as well as in seeds [45-47]. Over-expression of LEA protein genes, OsEM1, and OsLEA3-1 make rice drought stress-tolerant $[48,49]$. Similarly, high cuticular wax in many crops imparts tolerance to drought (Xue et al., 2017). Crops with high cuticular wax display more drought-tolerance [50-52]. Under drought stress conditions, DEEPER ROOTING 1 
increases rice yield and control of root system architecture [53]. Overexpressing heatshock protein OsHSP50. 2 improves drought tolerance in rice [54]. Natural variation in OsLG3 increases drought tolerance in rice by inducing ROS scavenging [55]. Overexpression of an MYB family gene, OsMYB6, increases drought and salinity stress tolerance in transgenic rice [56]. A stress-responsive bZIP transcription factor OsbZIP62 improves drought and oxidative tolerance in rice [57]. Characterization of transcription factor gene OsDRAP1 conferring drought tolerance in rice [58]. Overexpression of OsNAC14 improves drought stress tolerance in rice [59]. Rice WRKY11 plays a role in drought tolerance [60].

\subsection{Molecular breeding approach}

The complex drought tolerance mechanism is controlled by multiple quantitative trait loci (QTLs) [61]. Advances in plant physiology, and plant genomics, and phenotyping lead to new drought-tolerant varieties. By using the latest tools and gene network information, crop breeders will be able to increase crop yields [62]. Traditional molecular breeding methods can be used to explore QTLs for crop drought improvement, and later the candidate genes within drought associated QTL can be the primary targets for raising drought-tolerant transgenic lines [20].

The QTLs are part of the chromosome with specific positioned marker and contain several genes [63]. In rice, many drought-related QTLs have been identified (Table 2). qDTY1.1, 
a major QTL with an additive effect on grain yield under drought stress at the reproductive stage in three populations: N22/MTU1010, N22/IR64, and, N22/Swarna, was situated on rice chromosome 1. It is flanked by RM431 and RM11943 marker [64].

\section{Conclusions and perspectives}

In plants, drought stress signaling is very complicated process because of the many gene families and the complex molecular interactions between TFs with the cis-elements on the promoters of target genes. Also, one transcription factor can regulate many candidate genes with the corresponding cis-elements, whereas different families of TFs can regulate a single gene. Thus, the stress-responsive TFs not only work individually but also crosstalk with each other during drought stress response, which adds more complexity to the signaling networks that are involved in the plant stress responses. For future research work, we should first focus on multiple stress-responsive TF genes that can be regulated commonly by drought stress and have important role in the drought stress signaling crosstalk [65]. Genetic engineering of these identified stress-responsive genes should give us powerfull platform for improving plant drought stress tolerance. Furthermore, the vital drought stress field trials are required to evaluate the transgenetic plants, primarily focusing on their yield, growth under the drought stress. It will be one of the necessary steps in many strategies to develop drought stress-tolerant rice. Taken together, we still 
need to work hard for a complete understanding the precise drought stress responses regulatory mechanisms in rice. It will help us to obtain the candidate TF genes for breeding multiple drought stress-tolerant rice crops with better quality and yields.

1. FAO, F. Agriculture Organization of the United Nations (2008), Climate Change and Food Security: A Framework Document. Rome.

2. Thornton, P.K.; Ericksen, P.J.; Herrero, M.; Challinor, A.J. Climate variability and vulnerability to climate change: a review. Global Change Biol 2014, 20, 3313-3328, doi:10.1111/gcb.12581.

3. Kumar, M. Crop plants and abiotic stresses. J. Biomol. Res. Ther 2013, 3.

4. Kumar, K.; Kumar, M.; Kim, S.R.; Ryu, H.; Cho, Y.G. Insights into genomics of salt stress response in rice. Rice 2013, 6, doi:Artn 27,10.1186/1939-8433-6-27.

5. Kumar, M.; Gho, Y.S.; Jung, K.H.; Kim, S.R. Genome-Wide Identification and Analysis of Genes, Conserved between japonica and indica Rice Cultivars, that Respond to Low-Temperature Stress at the Vegetative Growth Stage. Frontiers in Plant Science 2017, 8, doi:ARTN 1120,10.3389/fpls.2017.01120.6. Kumar, M.; Kesawat, M.S. Mechanism of Salt Stress Tolerance and Pathways in Crop Plants. In Metabolic Adaptations in Plants During Abiotic Stress, CRC Press: 2018; pp. 27-44.

7. Ray, D.K.; West, P.C.; Clark, M.; Gerber, J.S.; Prishchepov, A.V.; Chatterjee, S. Climate change has likely already affected global food production. Plos One 2019, 14, doi:ARTN e0217148,10.1371/journal.pone.0217148.

8. Rosenzweig, C.; Elliott, J.; Deryng, D.; Ruane, A.C.; Muller, C.; Arneth, A.; Boote, K.J.; Folberth, C.; Glotter, M.; Khabarov, N., et al. Assessing agricultural risks of climate change in the 21st century in a global gridded crop model intercomparison (vol 111, pg 3268, 2013). P Natl Acad Sci USA 2016, 113, E665-E665, doi:10.1073/pnas.1600146113.

9. lizumi, T.; Sakuma, H.; Yokozawa, M.; Luo, J.J.; Challinor, A.J.; Brown, M.E.; Sakurai, G.; Yamagata, T. Prediction of seasonal climate-induced variations in global food production. Nat Clim Change 2013, 3, 904-908, doi:10.1038/Nclimate1945.

10. Birch, E.L. Climate Change 2014: Impacts, Adaptation, and Vulnerability. J Am Plann Assoc 2014, 80, 184-185, doi:10.1080/01944363.2014.954464. 
11. Lobell, D.B.; Roberts, M.J.; Schlenker, W.; Braun, N.; Little, B.B.; Rejesus, R.M.; Hammer, G.L. Greater Sensitivity to Drought Accompanies Maize Yield Increase in the US Midwest. Science 2014, 344, 516-519, doi:10.1126/science.1251423.

12. Dash, P.K.; Cao, Y.; Jailani, A.K.; Gupta, P.; Venglat, P.; Xiang, D.; Rai, R.; Sharma, R.; Thirunavukkarasu, N.; Abdin, M.Z., et al. Genome-wide analysis of drought induced gene expression changes in flax (Linum usitatissimum). GM Crops Food 2014, 5, 106-119, doi:10.4161/gmcr.29742.

13. Shinozaki, K.; Yamaguchi-Shinozaki, K. Gene networks involved in drought stress response and tolerance. J Exp Bot 2007, 58, 221-227, doi:10.1093/jxb/erl164.

14. Golldack, D.; Li, C.; Mohan, H.; Probst, N. Tolerance to drought and salt stress in plants: Unraveling the signaling networks. Front Plant Sci 2014, 5, 151, doi:10.3389/fpls.2014.00151.

15. $\mathrm{Hu}, \mathrm{H}$.; Xiong, L. Genetic engineering and breeding of drought-resistant crops. Annu Rev Plant Biol 2014, 65, 715-741, doi:10.1146/annurev-arplant-050213040000.

16. Yamaguchi-Shinozaki, K.; Shinozaki, K. Transcriptional regulatory networks in cellular responses and tolerance to dehydration and cold stresses. Annu Rev Plant Biol 2006, 57, 781-803, doi:10.1146/annurev.arplant.57.032905.105444.

17. Joshi, R.; Wani, S.H.; Singh, B.; Bohra, A.; Dar, Z.A.; Lone, A.A.; Pareek, A.; Singla-Pareek, S.L. Transcription Factors and Plants Response to Drought Stress: Current Understanding and Future Directions. Front Plant Sci 2016, 7, 1029, doi:10.3389/fpls.2016.01029.

18. Kumar, M.; Choi, J.; An, G.; Kim, S.R. Ectopic Expression of OsSta2 Enhances Salt Stress Tolerance in Rice. Frontiers in Plant Science 2017, 8, doi:ARTN 316,10.3389/fpls.2017.00316.

19. Lata, C.; Muthamilarasan, M.; Prasad, M. Drought stress responses and signal transduction in plants. In Elucidation of abiotic stress signaling in plants, Springer: 2015; pp. 195-225.

20. Varshney, R.K.; Bansal, K.C.; Aggarwal, P.K.; Datta, S.K.; Craufurd, P.Q. Agricultural biotechnology for crop improvement in a variable climate: hope or hype? Trends Plant Sci 2011, 16, 363-371, doi:10.1016/j.tplants.2011.03.004.

21. Todaka, D.; Shinozaki, K.; Yamaguchi-Shinozaki, K. Recent advances in the dissection of drought-stress regulatory networks and strategies for development of drought-tolerant transgenic rice plants. Front Plant Sci 2015, 6, 84, doi:10.3389/fpls.2015.00084.

22. Sah, S.K.; Reddy, K.R.; Li, J. Abscisic Acid and Abiotic Stress Tolerance in Crop Plants. Front Plant Sci 2016, 7, 571, doi:10.3389/fpls.2016.00571.

23. Kumar, M.; Lee, S.C.; Kim, J.Y.; Kim, S.J.; Aye, S.S.; Kim, S.R. Over-expression of dehydrin gene, OsDhn1, improves drought and salt stress tolerance through scavenging of reactive oxygen species in rice (Oryza sativa L.). J Plant Biol 2014, 57, 383-393, doi:10.1007/s12374-014-0487-1.

24. Maruyama, K.; Todaka, D.; Mizoi, J.; Yoshida, T.; Kidokoro, S.; Matsukura, S.; Takasaki, H.; Sakurai, T.; Yamamoto, Y.Y.; Yoshiwara, K. Identification of cisacting promoter elements in cold-and dehydration-induced transcriptional pathways in Arabidopsis, rice, and soybean. DNA research 2011, 19, 37-49. 
25. Mustilli, A.C.; Merlot, S.; Vavasseur, A.; Fenzi, F.; Giraudat, J. Arabidopsis OST1 protein kinase mediates the regulation of stomatal aperture by abscisic acid and acts upstream of reactive oxygen species production. Plant Cell 2002, 14, 30893099, doi:10.1105/tpc.007906.

26. Kwak, J.M.; Mori, I.C.; Pei, Z.M.; Leonhardt, N.; Torres, M.A.; Dangl, J.L.; Bloom, R.E.; Bodde, S.; Jones, J.D.; Schroeder, J.I. NADPH oxidase AtrbohD and AtrbohF genes function in ROS-dependent ABA signaling in Arabidopsis. EMBO J 2003, 22, 2623-2633, doi:10.1093/emboj/cdg277.

27. Wang, P.; Song, C.P. Guard-cell signalling for hydrogen peroxide and abscisic acid. New Phytol 2008, 178, 703-718, doi:10.1111/j.1469-8137.2008.02431.x.

28. Huang, X.Y.; Chao, D.Y.; Gao, J.P.; Zhu, M.Z.; Shi, M.; Lin, H.X. A previously unknown zinc finger protein, DST, regulates drought and salt tolerance in rice via stomatal aperture control. Genes Dev 2009, 23, 1805-1817, doi:10.1101/gad.1812409.

29. Sanders, D.; Brownlee, C.; Harper, J.F. Communicating with calcium. Plant Cell 1999, 11, 691-706, doi:10.1105/tpc.11.4.691.

30. Ramanjulu, S.; Bartels, D. Drought- and desiccation-induced modulation of gene expression in plants. Plant Cell Environ 2002, 25, 141-151.

31. Das, R.; Pandey, G.K. Expressional analysis and role of calcium regulated kinases in abiotic stress signaling. Curr Genomics 2010, 11, 2-13, doi:10.2174/138920210790217981.

32. Tena, G.; Boudsocq, M.; Sheen, J. Protein kinase signaling networks in plant innate immunity. Curr Opin Plant Biol 2011, 14, 519-529, doi:10.1016/j.pbi.2011.05.006.

33. Seybold, H.; Trempel, F.; Ranf, S.; Scheel, D.; Romeis, T.; Lee, J. Ca2+ signalling in plant immune response: from pattern recognition receptors to $\mathrm{Ca} 2+$ decoding mechanisms. New Phytol 2014, 204, 782-790.

34. Ning, J.; Li, X.; Hicks, L.M.; Xiong, L. A Raf-like MAPKKK gene DSM1 mediates drought resistance through reactive oxygen species scavenging in rice. Plant Physiol 2010, 152, 876-890, doi:10.1104/pp.109.149856.

35. Ouyang, S.Q.; Liu, Y.F.; Liu, P.; Lei, G.; He, S.J.; Ma, B.; Zhang, W.K.; Zhang, J.S.; Chen, S.Y. Receptor-like kinase OsSIK1 improves drought and salt stress tolerance in rice (Oryza sativa) plants. Plant $J$ 2010, 62, 316-329, doi:10.1111/j.1365-313X.2010.04146.x.

36. Umezawa, T.; Fujita, M.; Fujita, Y.; Yamaguchi-Shinozaki, K.; Shinozaki, K. Engineering drought tolerance in plants: discovering and tailoring genes to unlock the future. Curr Opin Biotechnol 2006, 17, 113-122, doi:10.1016/j.copbio.2006.02.002.

37. Licausi, F.; Ohme-Takagi, M.; Perata, P. APETALA2/Ethylene Responsive Factor (AP2/ERF) transcription factors: mediators of stress responses and developmental programs. New Phytol 2013, 199, 639-649.

38. Castilhos, G.; Lazzarotto, F.; Spagnolo-Fonini, L.; Bodanese-Zanettini, M.H.; Margis-Pinheiro, M. Possible roles of basic helix-loop-helix transcription factors in adaptation to drought. Plant Sci 2014, 223, 1-7, doi:10.1016/j.plantsci.2014.02.010. 
39. Shao, H.B.; Wang, H.Y.; Tang, X.L. NAC transcription factors in plant multiple abiotic stress responses: progress and prospects. Frontiers in Plant Science 2015, 6, doi:ARTN 902,10.3389/fpls.2015.00902.

40. Srivasta, A.; Mehta, S.; Lindlof, A.; Bhargava, S. Over-represented promoter motifs in abiotic stress-induced DREB genes of rice and sorghum and their probable role in regulation of gene expression. Plant Signal Behav 2010, 5, 775-784, doi:10.4161/psb.5.7.11769.

41. Nakashima, K.; Yamaguchi-Shinozaki, K.; Shinozaki, K. The transcriptional regulatory network in the drought response and its crosstalk in abiotic stress responses including drought, cold, and heat. Frontiers in Plant Science 2014, 5, doi:ARTN 170,10.3389/fpls.2014.00170.

42. Datta, K.; Baisakh, N.; Ganguly, M.; Krishnan, S.; Yamaguchi Shinozaki, K.; Datta, S.K. Overexpression of Arabidopsis and rice stress genes' inducible transcription factor confers drought and salinity tolerance to rice. Plant Biotechnol J 2012, 10 , 579-586, doi:10.1111/j.1467-7652.2012.00688.x.

43. Hong, Y.; Zhang, H.; Huang, L.; Li, D.; Song, F. Overexpression of a StressResponsive NAC Transcription Factor Gene ONAC022 Improves Drought and Salt Tolerance in Rice. Front Plant Sci 2016, 7, 4, doi:10.3389/fpls.2016.00004.

44. Goyal, K.; Walton, L.J.; Tunnacliffe, A. LEA proteins prevent protein aggregation due to water stress. Biochem J 2005, 388, 151-157, doi:10.1042/Bj20041931.

45. Ingram, J.; Bartels, D. The Molecular Basis of Dehydration Tolerance in Plants. Annu Rev Plant Physiol Plant Mol Biol 1996, 47, 377-403, doi:10.1146/annurev.arplant.47.1.377.

46. He, S.; Tan, L.L.; Hu, Z.L.; Chen, G.P.; Wang, G.X.; Hu, T.Z. Molecular characterization and functional analysis by heterologous expression in $\mathrm{E}$. coli under diverse abiotic stresses for OsLEA5, the atypical hydrophobic LEA protein from Oryza sativa L. Mol Genet Genomics 2012, 287, 39-54, doi:10.1007/s00438011-0660-X.

47. Liu, Y.; Wang, L.; Xing, X.; Sun, L.; Pan, J.; Kong, X.; Zhang, M.; Li, D. ZmLEA3, a multifunctional group 3 LEA protein from maize (Zea mays L.), is involved in biotic and abiotic stresses. Plant Cell Physiol 2013, 54, 944-959, doi:10.1093/pcp/pct047.

48. Xiao, B.; Huang, Y.; Tang, N.; Xiong, L. Over-expression of a LEA gene in rice improves drought resistance under the field conditions. Theor Appl Genet 2007, 115, 35-46, doi:10.1007/s00122-007-0538-9.

49. Yu, J.; Lai, Y.M.; Wu, X.; Wu, G.; Guo, C.K. Overexpression of OsEm1 encoding a group I LEA protein confers enhanced drought tolerance in rice. Biochem Bioph Res Co 2016, 478, 703-709, doi:10.1016/j.bbrc.2016.08.010.

50. Zhou, L.Y.; Ni, E.D.; Yang, J.W.; Zhou, H.; Liang, H.; Li, J.; Jiang, D.G.; Wang, Z.H.; Liu, Z.L.; Zhuang, C.X. Rice OsGL1-6 Is Involved in Leaf Cuticular Wax Accumulation and Drought Resistance. Plos One 2013, 8, doi:UNSP e65139,10.1371/journal.pone.0065139.

51. Guo, J.; Xu, W.; Yu, X.C.; Shen, H.; Li, H.S.; Cheng, D.G.; Liu, A.F.; Liu, J.J.; Liu, C.; Zhao, S.J., et al. Cuticular Wax Accumulation Is Associated with Drought 
Tolerance in Wheat Near-Isogenic Lines. Frontiers in Plant Science 2016, 7, doi:ARTN 1809,10.3389/fpls.2016.01809.

52. Zhu, X.Y.; Xiong, L.Z. Putative megaenzyme DWA1 plays essential roles in drought resistance by regulating stress-induced wax deposition in rice. P Natl Acad Sci USA 2013, 110, 17790-17795, doi:10.1073/pnas.1316412110.

53. Uga, Y.; Sugimoto, K.; Ogawa, S.; Rane, J.; Ishitani, M.; Hara, N.; Kitomi, Y.; Inukai, Y.; Ono, K.; Kanno, N., et al. Control of root system architecture by DEEPER ROOTING 1 increases rice yield under drought conditions. Nat Genet 2013, 45, 1097-+, doi:10.1038/ng.2725.

54. Xiang, J.; Chen, X.; Hu, W.; Xiang, Y.; Yan, M.; Wang, J. Overexpressing heatshock protein OsHSP50. 2 improves drought tolerance in rice. Plant cell reports 2018, 37, 1585-1595.

55. Xiong, H.; Yu, J.; Miao, J.; Li, J.; Zhang, H.; Wang, X.; Liu, P.; Zhao, Y.; Jiang, C.; Yin, Z. Natural variation in OsLG3 increases drought tolerance in rice by inducing ROS scavenging. Plant physiology 2018, 178, 451-467.

56. Tang, Y.; Bao, X.; Zhi, Y.; Wu, Q.; Yin, X.; Zeng, L.; Li, J.; Zhang, J.; He, W.; Liu, W. Overexpression of a MYB family gene, OsMYB6, increases drought and salinity stress tolerance in transgenic rice. Frontiers in plant science 2019, 10, 168.

57. Yang, S.; Xu, K.; Chen, S.; Li, T.; Xia, H.; Chen, L.; Liu, H.; Luo, L. A stressresponsive bZIP transcription factor OsbZIP62 improves drought and oxidative tolerance in rice. BMC plant biology 2019, 19, 260.

58. Huang, L.; Wang, Y.; Wang, W.; Zhao, X.; Qin, Q.; Sun, F.; Hu, F.; Zhao, Y.; Li, Z.; Fu, B. Characterization of transcription factor gene OsDRAP1 conferring drought tolerance in rice. Frontiers in plant science 2018, 9, 94.

59. Shim, J.S.; Oh, N.; Chung, P.J.; Kim, Y.S.; Choi, Y.D.; Kim, J.-K. Overexpression of OsNAC14 improves drought tolerance in rice. Frontiers in plant science 2018, $9,310$.

60. Lee, H.; Cha, J.; Choi, C.; Choi, N.; Ji, H.-S.; Park, S.R.; Lee, S.; Hwang, D.-J. Rice WRKY11 plays a role in pathogen defense and drought tolerance. Rice 2018, $11,5$.

61. Fleury, D.; Jefferies, S.; Kuchel, H.; Langridge, P. Genetic and genomic tools to improve drought tolerance in wheat. $J$ Exp Bot 2010, 61, 3211-3222, doi:10.1093/jxb/erq152.

62. Tuberosa, R. Phenotyping for drought tolerance of crops in the genomics era. Front Physiol 2012, 3, 347, doi:10.3389/fphys.2012.00347.

63. Chamarthi, S.; Kumar, A.; Vuong, T.; Blair, M.; Gaur, P.; Nguyen, H.; Varshney, R. 19 Trait Mapping and Molecular Breeding. Biology and breeding of food legumes 2011, 296.

64. Vikram, P.; Swamy, B.P.M.; Dixit, S.; Ahmed, H.U.; Cruz, M.T.S.; Singh, A.K.; Kumar, A. qDTY(1.1), a major QTL for rice grain yield under reproductive-stage drought stress with a consistent effect in multiple elite genetic backgrounds. Bmc Genet 2011, 12, doi:Artn 89,10.1186/1471-2156-12-89. 
65. Prasch, C.M.; Sonnewald, U. Signaling events in plants: Stress factors in combination change the picture. Environ Exp Bot 2015, 114, 4-14, doi:10.1016/j.envexpbot.2014.06.020.

Figure Legends

Figure 1. Overview of regulatory network of Drought stress signaling in Rice. 